\title{
Human Subsistence Strategies and Adaptations in the Lower Yangtze River Region During the Prehistoric Era
}

\author{
Yaowu $\mathrm{Hu}^{1,2 *}$ \\ ${ }^{1}$ Department of Cultural Heritage and Museology, Fudan University, Shanghai, China, ${ }^{2}$ Institute of Archaeological Science, \\ Fudan University, Shanghai, China
}

Understanding the human subsistence strategies and adaptations in the Lower Yangtze River Region during the prehistoric period is vital to reveal the human-environment interactions, the origin and development of rice agriculture, cultural development, and social complexity. No systematic analysis of isotopic data of human bones in the region has been undertaken within the environmental (sea level), spatiotemporal (site distribution), and economic (animal and plant resources) contexts yet, in order to provide the direct evidence of human diets and trajectory of human subsistence strategies and adaptations. In this

OPEN ACCESS

Edited by: Guanghui Dong, Lanzhou University, China

Reviewed by:

Li Wu,

Anhui Normal University, China

Tengwen Long,

University of Nottingham Ningbo

China, China

*Correspondence:

Yaowu Hu

ywhu@fudan.edu.cn

Specialty section:

This article was submitted to Quaternary Science, Geomorphology and Paleoenvironment,

a section of the journal Frontiers in Earth Science

Received: 16 January 2021 Accepted: 10 February 2021

Published: 10 March 2021

Citation:

Hu Y (2021) Human Subsistence Strategies and Adaptations in the Lower Yangtze River Region During the

Prehistoric Era.

Front. Earth Sci. 9:654416. doi: 10.3389/feart.2021.654416 paper, I collected the isotopic data in the region as many as possible and incorporated within the environmental, spatiotemporal, and economic information. The results show that humans rarely made use of marine resources when facing the situation of rising sea levels and having good accesses to marine environment during the eastward movement. Alternatively, humans consumed large amount of terrestrial resources and supplementary freshwater or wetland resources. Rice agriculture was still of low-level production and contributed less to human diets. The unique human subsistence strategies enhanced human adaptations to the fluctuation of sea level in the Holocene in eastern China and facilitated the increases of archaeological cultures and human population, challenging the traditional opinion that the developed agriculture is the necessary pathway to develop cultures and grow human population.

Keywords: the lower Yangtze River region, human-environment interaction, stable isotope analysis, subsistence strategy, adaptation

\section{INTRODUCTION}

In recent years, more and more archaeological evidence has shown that the Lower Yangtze River Region (LYRR), including the Ningshao Plain, the Hangiiahu Plain and areas around Taihu Lake, is not only the birthplace of rice agriculture but also one of the important places for the occurrence of Chinese civilization, paralleling to that in the Yellow River Valley (e.g., Renfrew and Liu, 2018). Different from those in the Yellow River Valley, human activities in the LYRR are quite sensitive to and highly influenced by the fluctuation of sea levels in the Holocene as the region is located in the east of China and close to the coastline. Understanding human subsistence strategies and adaptations in prehistoric periods is critical to reveal the human-environment interaction, the origin and development of rice agriculture, cultural developments, and the formation of social complexity. 
TABLE 1 The chronology of cultures in the LYRR (revised from Pan and Yuan, 2018).

\section{Culture}

Dates ( BC)

\section{Shangshan}

Kuahuqiao

Hemudu (ningshao plain)

Majiabang (area around taihu)

Songze

Liangzhu

Qianshanyang

Guangfulin

Maqiao

9400-6500

$6200-5000$

$5000-3800$

$5000-4000$

4000-3300

$3300-2300$

2300-2000

2300-2000

$1900-1200$

So far, several methods have been applied to investigating human diets in the LYRR, such as paleobotanical analysis, archaeozoological analysis, residue analysis and stable isotope analysis. Among them, the analyses of animal and plant remains (carbonized plants and microfossils such as phytolith, pollen and starch grains) have been widely used to reveal the origin and development of rice agriculture and exploitation of animal resources (wild and domesticated animals) (e.g., Pan and Yuan, 2018; Pan and Yuan, 2019). The residues preserved in the prehistoric pottery have been preliminarily analyzed to identify the animal or plant resources (Shoda et al., 2018), providing another effective way to reveal human diets in short periods. In contrast, the stable isotope $\left(\delta^{13} \mathrm{C}, \delta^{15} \mathrm{~N}\right)$ analysis of human bones can offer the direct evidence of human diets during long-term periods before the individual's death and has been increasingly used to reveal human subsistence strategies in China (e.g., Hu, 2018). Given the fact that human bones in the LYRR are generally not preserved well, the isotopic studies are not as popular as those in the Yellow River Valley. However, the accumulation of isotopic data in recent years makes it possible for us to trace back human diets and their diachronic shifts in the prehistoric periods. To our knowledge, no systematic analysis of isotopic data has been undertaken within the environmental (sea level), spatiotemporal (site distribution), economic (animal and plant resources) contexts yet.

In this paper, I collected the isotopic data of human bones in the LYRR as many as possible and focused on interpreting human diets and activities on the basis of reviewing the chronology of prehistoric cultures, the fluctuation of sea level, the distribution of sites, and the utilization of plant and animal resources. My aim was to reveal the interactions among sea levels, archaeological cultures, and human subsistence strategies in the LYRR and discuss the impacts of the fluctuation of sea levels on human activities and human adaptations to the unstable environment.

\section{CONTEXTS}

\section{Chronological Context: Chronology of Prehistoric Cultures in the LYRR}

Continuous archaeological excavations and studies have established the chronological framework of archaeological cultures in the LYRR. Here, I cited the chronology of prehistoric cultures outlined by Pan and Yuan (2018) and listed it in Table 1.

\section{Environmental Context: The Fluctuation of Sea Levels in the LYRR}

The LYRR is near the coastline in east China. Different from that in the Yellow River Valley, the most important climatic factor to influence cultural development and human activities in the LYRR during the Holocene is the fluctuation of sea levels after the Last Glacial Maximum and extreme environmental events such as sea transgression, sea flooding and storms (Wang et al., 2018). Thus, understanding of the fluctuation of sea levels and coastline is the prerequisite to understand the distribution of archaeological sites, human living environment and subsistence strategies.

The model of global sea level curve constructed by Lambeck et al. (2014), is regarded as one of the best and most reliable curves as it synthesized more than a thousand points data of sediment cores worldwide and incorporated global ice volume modeling (Zheng et al., 2018). It suggests that: 1) sea level rose rapidly since the Last Deglaciation by $10-15 \mathrm{~m}$ from 21 to $18 \mathrm{ka}$, and kept constant during the next $1.5 \mathrm{ka}(18-16.5 \mathrm{ka}) ; 2)$ during the period of $16.5-7.0 \mathrm{ka}$, sea level rose by about $120 \mathrm{~m}$ and reached to -5 to $-3 \mathrm{~m}$ at $7.0 \mathrm{ka} ; 3)$ after $7 \mathrm{ka}$, the rise of sea level decelerated significantly and remained relatively stable (Lambeck et al., 2014).

There are several differences of sea level curve models on millennial scale reconstructed from various sediment cores along Chinese east coastline from the above model. Yang and Xie (1984) and Zhao et al. (1994) suggest that sea level was higher than today around $6 \mathrm{ka}$ and fell to the present level gradually while Liu et al. (2004) propose that the sea level during 6.5-7.0 ka was higher than today. Song et al. (2013) claim that the high sea level was present around $5 \mathrm{ka}$ and kept constant since then. Recent study indicates the sea level close to the present might occur c. 8.0-7.5 cal. ka BP and decline c. 7.6-7.5 cal. ka BP (Yan et al., 2020). Whereas, Xiong et al. (2020) think that the rise of sea level from $c .-38.3 \pm 1.6 \mathrm{~m}$ to the present height happened from $c$. $10000 \mathrm{cal}$. a BP to $7000 \mathrm{cal}$. a BP with the uneven average rate of sea-level rise and that the rise and fall of sea level also took place between 7000 and $4000 \mathrm{cal}$. a BP.

In summary, sea level in the east China coastline rose around $20000 \mathrm{BP}$ and approached to the present height c. $7000 \mathrm{BP}$ and might have fluctuated differently in varied areas of the LYRR along the coastline.

\section{Spatiotemporal Context: The Spatial and Temporal Distribution of Archaeological Sites}

The fluctuation of sea level in the Holocene has strong impact on humans to settle down in the prehistoric periods. The investigation of over 2000 sites dated to the prehistory and Shang and Zhou Dynasties using DEM and GIS methods (Zheng et al., 2018) provides the good opportunity for us to look at the spatial and temporal distribution of archaeological sites in the LYRR. During the period of 1000-8500 BP, the sites were sparsely in the basins and far from the sea (Zheng et al., 2018). During the period of 
TABLE 2 | The animal and plant species mainly used in different periods (modified from Pan and Yuan, 2019).

\begin{tabular}{lccccc}
\hline $\begin{array}{l}\text { Period (BP) } \\
\text { Food }\end{array}$ & $\mathbf{1 1 0 0 0 -}$ & $\mathbf{8 2 0 0}$ & $\mathbf{6 0 0 0}$ & $\mathbf{5 3 0 0}$ & $\mathbf{4 3 0 0 -}$ \\
category & $\mathbf{8 4 0 0}$ & $\mathbf{6 0 0 0}$ & $\mathbf{5 3 0 0}$ & $\mathbf{4 3 0 0}$ & $\mathbf{2 3 0 0}$ \\
\hline Rice & & & & & \\
Foxnut & + & + & ++ & +++ & ++ \\
Water & + & ++ & + & + & + \\
chestnut & & ++++ & + & + & + \\
Fagaceae nut & & & & & + \\
Millets & & +++ & & & + \\
Dog & & & & + & + \\
Pig & & + & + & + & + \\
Deer & & + & + & ++ & + \\
Bird & & +++ & ++ & + & + \\
Fish & & + & + & + & + \\
& & + & + & + & + \\
\hline
\end{tabular}

Note: The number of "+" indicates the increase of the percentage among foods.

9000-7000 BP, the sea transgression occurred. About $7000 \mathrm{BP}$, the rise of sea level slowed down and sea level was close to the present height (Zheng et al., 2018). The decrease of sea level rise made the land exposed, which resulted in the lower Yangtze River delta (Zheng et al., 2018). The regression of coastline and expansion of lands eastwards offered a wide space for the development of Neolithic cultures. In this period, the number and size of sites increased dramatically and the distribution of sites went eastwards (Zheng et al., 2018). Around 4000 BP, the number of sites decreased greatly and only the sites belonging to the Guangfulin and Qianshanyang cultures existed.

In the meantime, the sea transgression or extreme environmental events had great influence on the disruption of the archaeological sites and cultures, which can also be uncovered in the sediment cores. The Kuahuqiao site might be inundated by the rise of sea level around $7400 \mathrm{cal}$. BP (Pan, 2020). The sea transgression at the Yaojiang-Ningbo Plain during the periods of 6300-6000 BP, 5400-5300 BP and 4500-3400 BP caused the lacking of continuous deposits of archaeological cultures (Tang et al., 2019). This phenomenon was also observed at sites dating to the Hemudu Culture (Ouyang et al., 2019; He et al., 2020). In particular, the coastal flooding occurring $4.5 \mathrm{cal}$. ka BP could have been a major reason accounting for the diminishment and abandonment of the Liangzhu Culture around $4.4 \mathrm{cal}$. ka BP (Wang et al., 2020). Besides, Ling et al. (2021) note that overbank flooding or storm surge events happened at the Liangzhu Ancient City area during the middle to late Holocene (after c. 7600 cal. BP).

In brief, human settlements and archaeological cultures in the LYRR were highly influenced by the fluctuation of sea level. The sea regression and transgression as well as extreme environmental events (flood, storm, typhoon, etc.) can be regarded as one of the important factors to influence the flourishment and abandonment of archaeological sites and cultures.

\section{Economic Context: The Animal and Plant Resources Used by Humans in the LYRR}

The fauna and flora assemblages collected at the archaeological sites in the LYRR create a good opportunity for us to understand the animal and plant resources used by humans. Here, I follow the summary proposed by Pan and Yuan (2018); Pan and Yuan (2019) to reveal the shift of animal and plant resources through time.

Pan and Yuan (2018); Pan and Yuan (2019) systematically summed up the main animal and plant remains from 57 archaeological sites and suggested the following trajectory of animal and plant resources utilized by humans (Table 2). During the period of $11000-8400 \mathrm{BP}$, representative of the Shangshan culture, humans greatly relied on the hunting, fishing and gathering and cultivated rice as supplement. During the period of 8200-5300 BP, represented by the Kuahuqiao, Hemudu, Majiabang, Songze cultures, humans relied mainly on hunting, fishing, and gathering (shells). The cultivation of rice, the animal husbandry (pigs and dogs) developed further and many kinds of freshwater plant resources were also utilized. During the period of 5300-4300 $\mathrm{BP}$, typical of Liangzhu Culture, the rice agriculture was intensified and raising pigs became more popular with other plant resources (fruits) exploited. There might have been subsistence distinction between the central and suburb settlements. During the period of 4300-2300 BP, representative of the Guangfulin, Qianjiayang, Maqiao Cultures, the rice agriculture and animal husbandry decreased and millets came into this region in the ShangZhou dynasties.

In Table 2 can infer that the marine resources had never been one of main food components in human menu in the LYRR even though they were found sparsely at several sites (Pan and Yuan, 2018; Pan and Yuan, 2019). In contrast, the terrestrial and freshwater resources were continuously made use of by humans in the prehistoric periods. The Jingtoushan site (Figure 1), the newly found earliest site (c. 8000 BP) near the coastline, could have been of an exception, where large quantity of marine foodstuff (shells) was found ( $\mathrm{He}$ and Lv, 2017; http:// kaogu.cssn.cn/zwb/kgyd/kgsb/202006/t20200609_5140596.shtml). Even though, terrestrial resources, such as rice and acorn, were also abundant at the site ( $\mathrm{He}$ and $\mathrm{Lv}, 2017$, suggesting that terrestrial resources were of necessary components in human foodways.

In addition, the events of sea transgression in the Holocene hamper the successive development of rice domestication. Rice phytolith analysis from more than 10 archaeological sites dating to 10000-2000 BP indicated that the ratio of bulliform phytolith with the numbers of fish-scale decoration higher or equal to 9 (domesticated rice) to that with the numbers of fish-scale decoration less than 9 (wild rice) did not always increase through time (Lv, 2017). This suggests that rice domestication was not straightforward and fluctuated at times. The fall of rice domestication during the periods of 7900-7400 BP and 6500-5600 BP might have been caused by the marine transgression ( $\mathrm{He}$ et al., 2020). Apparently, the marine transgression decreased the continuous rice domestication during the mid-Holocene in the LYRR ( $\mathrm{He}$ et al., 2020; He et al., 2020; Liu et al., 2020; Ma et al., 2020) and humans had to rely on diverse terrestrial and freshwater resources before the Liangzhu Culture. 


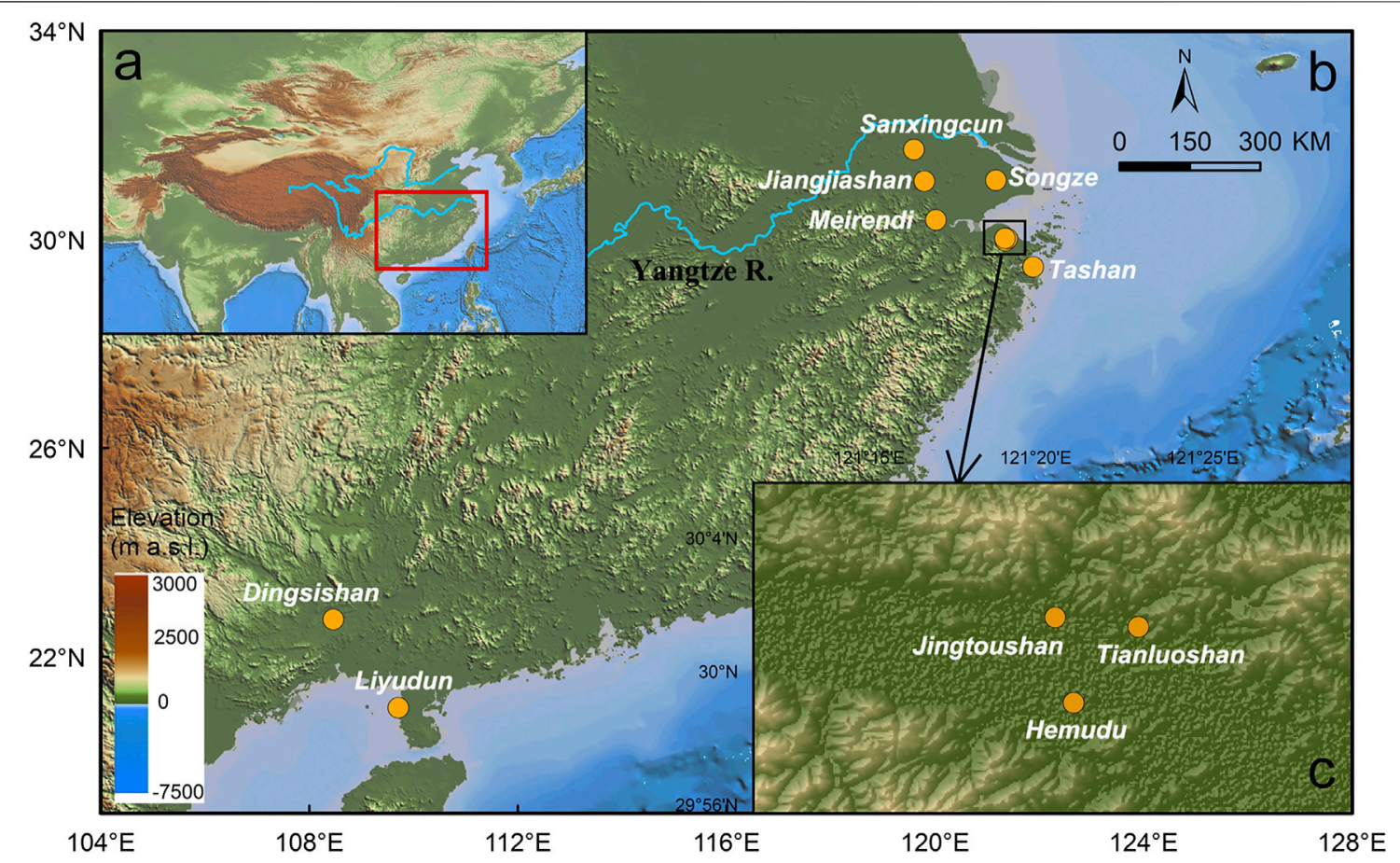

FIGURE 1 | The geographic location of archaeological sites edited by Bing Yi. (A) The study area; (B) Locations of archaeological sites mentioned in the text. (C) Enlarged locations of archaeological sites in the Ningshao Plain.

TABLE 3 | Collections of isotopic data of human bones in the LYRR.

\begin{tabular}{|c|c|c|c|c|c|c|c|}
\hline Site name & Dates (BP) & Mean $\delta^{13} \mathrm{C}(\% \circ)$ & Mean $\delta^{15} \mathrm{~N}(\% \circ)$ & $\begin{array}{c}\delta^{13} \mathrm{C}(\mathrm{SD}) \\
(\% \circ)\end{array}$ & $\delta^{15} \mathrm{~N}(\mathrm{SD})(\% \circ)$ & Sample number & References \\
\hline Songze & $6000-5300$ & -19.9 & 10.9 & 0.5 & 1.7 & 2 & Zhang et al. (2003) \\
\hline Hemudu & $7000-6000$ & -16.7 & 11.4 & 2.3 & 0.3 & 2 & Zhang et al. (2003) \\
\hline Sanxincun & $6500-5500$ & -20.1 & 9.7 & 0.21 & 0.3 & 19 & Hu et al. (2007) \\
\hline Liyudun & $7000-6000$ & -17 & 13.8 & 1.3 & 1.4 & 2 & Hu et al. (2010) \\
\hline Tianluoshan ${ }^{1}$ & $7000-6000$ & -20.7 & 8.7 & 0.5 & 0.9 & 10 & Minagawa et al. (2011) \\
\hline Tashan & $5900-5600$ & -18.4 & 9.2 & 0.5 & 0.7 & 3 & Zhang et al. (2015) \\
\hline Tianluoshan $^{2, \star}$ & $7000-6000$ & -20.6 & 9.0 & 0.5 & 0.9 & 10 & Dong (2016) \\
\hline Jiangjiashan* & $6900-5800$ & -20.5 & 10.2 & & & 1 & Yu (2016) \\
\hline Meirendi\# & $5300-4300$ & -19.8 & 10.5 & & & 9 & Yoneda (2017) \\
\hline Dingshishan & $9000-7000$ & -21.1 & 12.3 & 0.7 & 1.8 & 38 & Zhu et al. (2020) \\
\hline
\end{tabular}

${ }^{1}$ One abnormal isotopic data were deleted for discussion at both sites marked by "**.

${ }^{2}$ No isotopic data in detail were reported in the paper marked with "\#". The average isotopic data were estimated from the scatter plot by the author.

\section{Isotopic $\left(\delta^{13} \mathrm{C}, \delta^{15} \mathrm{~N}\right)$ Analysis of Human Bones in the LYRR}

The stable isotope analysis of human bones in China initiated in 1980 s and only until the 21st century is it not paid attention to by Chinese scholars (Hu, 2018). Zhang et al. (2003) reported the first isotopic data $\left(\delta^{13} \mathrm{C}, \delta^{15} \mathrm{~N}\right)$ of human bones in the LYRR. Subsequently, $\mathrm{Hu}$ et al. (2007) carried on the stable isotope analysis of human bones at the Sanxincun site, Jiangsu. Since 2010, the isotopic studies in the LYRR have increased and relatively rich isotopic data from human and animals have been accumulated. Compared to the summary of isotopic data (Chen, 2017; Qin and Fuller, 2019; Liu et al., 2021), we collected more isotopic data (Table 3) including the previously published and unpublished data as well as two reference groups from South China, in order to better understand human subsistence strategies and adaptation within the environmental, spatiotemporal, economic contexts in the region. The information on the site name, site location (Figure 1), date, the isotopic data and references is listed in Table 3 and the error bar plot is shown in Figure 2.

According to Table 3 and Figure 2, we can draw the following inferences:

1. Hardly humans consumed marine resources except those at Hemudu consuming a few marine resources, and relied heavily on terrestrial and/or freshwater foods. The LYRR is located 


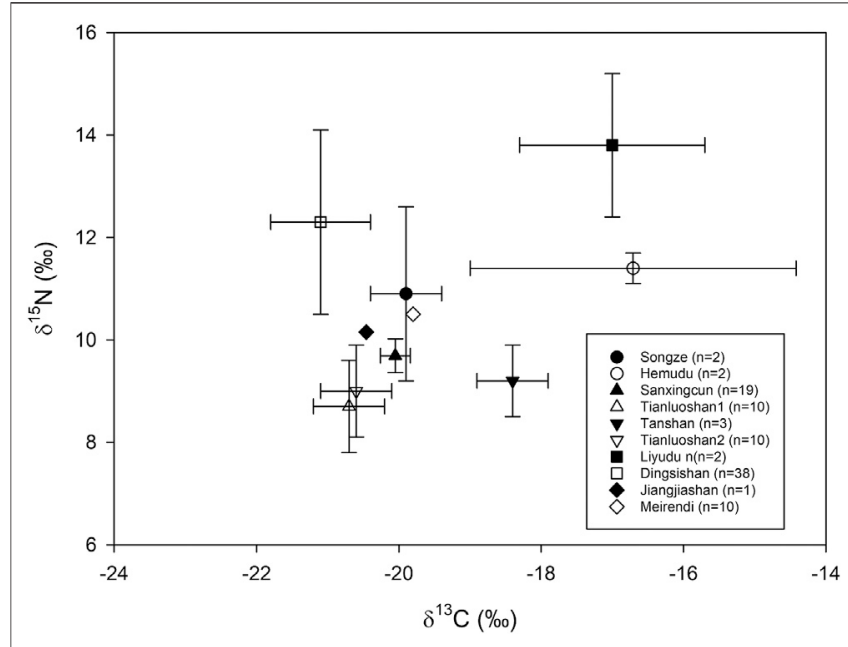

FIGURE 2 | The error bar plot of human bones in LYRR and South China.

near the China east coast. After $7000 \mathrm{BP}$, with the regression of sea levels and the expansion of lands, humans moved eastwards and occupied large lands exposed and might have had great accesses to marine foods. In general, humans consuming large quantity of marine resources should have much positive $\delta^{13} \mathrm{C}$ values and high $\delta^{15} \mathrm{~N}$ values such as those at Liyudun in Figure 4. It is so surprising for us to see that humans dating to 7000-5000 BP except those at Hemudu did not mainly consume marine foods during the process of population movements eastwards. In particular, humans at Tashan, closest to the coastline (Figure 1), did not consume any marine foods and mainly relied on terrestrial foods (Table 3; Figure 2). This unique dietary pattern of humans reflects that humans had conservative preference on terrestrial and/or freshwater resources even though they had great opportunity to obtain the seafoods. Our inference here is consistent with the opinion (Qin and Fuller, 2019) suggesting that the prehistoric humans in the LYRR were lack of the motives of exploiting marine resources.

2. Humans did not be mainly engaged in the hunting/fishing activities and consumed large quantity of terrestrial resources with some freshwater resources supplemented. In general, humans consuming a lot of freshwater fish have low $\delta^{13} \mathrm{C}$ and high $\delta^{15} \mathrm{~N}$ values such as those at Dingsishan in South China (Figure 2). Compared to those at Dingsishan, humans in the LYRR in Figure 2 have higher $\delta^{13} \mathrm{C}$ and lower $\delta^{15} \mathrm{~N}$ values, strongly indicating that their foods were deprived more from terrestrial surroundings and less from freshwater fish. This is in line with the archaeozoological finding (Table 2), indicating that fish was not one of important components in human diets even though they were present all the time. Instead, terrestrial animals (deer, pigs) or wetland plants with possible lower $\delta^{15} \mathrm{~N}$ values (rice including domesticated rice or wild rice, gorgon fruit, water chestnut, etc.) could have been the necessary compositions in human diets.
3. Human diets were diverse and shifted diachronically. Humans at Hemudu might consume some marine foods while those at Tianluoshan ate many plant resources. They could be deprived from several types of wetland plants, like rice, gorgon fruit, water chestnut (Pan and Yuan, 2018; Pan and Yuan, 2019) and typha (Zhang et al., 2020). The consumption of starchy plants was also confirmed by the residue analysis (Shoda et al., 2018). Different from those at Tianluoshan, humans at Jiangjiashan consumed more freshwater resources such as fish; humans at Songze mainly inhabited on the terrestrial and freshwater environment; humans at Tashan obtained their foods mainly from terrestrial environment and seldom from freshwater resources; humans at Sanxincun intensified the utilization of freshwater resources such as shells. It seems that humans at Meirendi escaped from the wetland environment and consumed more animal protein from freshwater resources or domestic animals. Given the popularity of pig husbandry during the Liangzhu Culture (Table 2), domestic pigs could have contributed more to animal resources at the site.

4. The cultivation of rice and its contribution to human diets vary in the different areas and periods. As indicated in Table 2, the domestication of rice has developed quickly around 70006000BP and matured around $5000 \mathrm{BP}$. In principle, if rice would be more and more incorporated in human diets, the decrease of $\delta^{15} \mathrm{~N}$ values from humans should have been expected as rice belongs to starchy plants with low nitrogen contents and has low $\delta^{15} \mathrm{~N}$ values in general (Suzuki et al., 2008). However, large isotopic difference among human populations can be seen in Figure 2, even though the domesticated rice is present in different periods and areas. This could be caused by the consumption of diverse terrestrial or freshwater resources. Therefore, no matter what rice is wild or domesticated, rice production by humans should have been of low-level. Humans at Meirendi in the core area of Liangzhu Culture have a little higher $\delta^{13} \mathrm{C}$ and $\delta^{15} \mathrm{~N}$ values than those in Tianluoshan (Figure 2) and the isotopic data don't show decreasing pattern as expected if rice agriculture was intensified during the period. Nevertheless, we should caution that given the limited isotopic data available here the current discussion on the contribution of rice agriculture to human subsistence strategy is still preliminary. More isotopic data are needed to prove or refute it in the near future.

\section{DISCUSSION}

It is traditionally supposed that the occurrence and development of agriculture is the key to increase the food production and satisfy with the population growth and the rise of social complexity (e.g., Gignoux et al., 2011). However, recent study (Lewis, et al., 2020) challenges the above standpoint.

The global increase of sea levels in the Holocene has great impact on human activities worldwide (Dong et al., 2020) and makes humans easily approach the marine resources. A number 
of isotopic studies show that humans close to the coastline have intensively consumed marine foods in Europe (Richards and Hedges, 1999; Montgomery, et al., 2013; Schulting, 2018), Japan (Kusaka et al., 2010), and South Korea (Choy et al., 2012) before the transition to agriculture. The adaptation of sea level increase by humans greatly expands food choices in human menu and stimulates the cultural developments and population increase in Southern Scandinavia before the arrival of agriculture (Lewis et al., 2020).

Compared to humans in Southern Scandinavia, the humans in the LYRR, however, adopted a quite different strategy when facing the rise of sea level in the Holocene as well. The economic (Table 2) and isotopic (Table 3; Figure 2) evidence strongly suggests that humans rarely relied on marine resources and consumed large quantity of terrestrial and/or freshwater resources (plants) instead, even though they had good accesses to marine environment. Before the Liangzhu Culture, the rice had been in low-level food production and contributed less to human diets for a long time. On the other hand, humans subsisted mainly on the terrestrial and freshwater or wetland resources. This unique subsistence strategy could possibly have made humans well adapt to unstable environment and sea transgression at times, which expanded the settlements and population subsequently and resulted in the social complexity. Therefore, our comprehensive study here illustrates a novel pattern of human subsistence strategy and adaption to increasing human population in the condition of low-level agricultural production, challenging the traditional view that only developed agriculture can make human population grow and advance human society.

\section{CONCLUSION}

Based on the introduction to environmental, spatiotemporal and economic contexts, this paper summarized the isotopic data of

\section{REFERENCES}

Chen, X. (2017). Stable isotope (C, N) analysis and the advances of agricultural archaeology. Agric. Archaeology 6, 13-25. (in Chinese).

Choy, K., An, D., and Richards, M. P. (2012). Stable isotopic analysis of human and faunal remains from the Incipient Chulmun (Neolithic) shell midden site of Ando Island, Korea. J. Archaeological Sci. 39 (7), 2091-2097. doi:10.1016/j.jas. 2012.03.005

Dong, G., Li, R., Lu, M., Zhang, D., and James, N. (2020). Evolution of humanenvironmental interactions in China from the late paleolithic to the bronze age. Prog. Phys. Geogr. Earth Environ. 44 (2), 233-250. doi:10.1177/ 0309133319876802

Dong, Y. (2016). Preliminary exploration of prehistoric human subsistence in Zhejiang coastline. Master's thesis. Hangzhou: Zhejiang University. (in Chinese).

Gignoux, C. R., Henn, B. M., and Mountain, J. L. (2011). Rapid, global demographic expansions after the origins of agriculture. Proc. Natl. Acad. Sci. USA 108 (15), 6044-6049. doi:10.1073/pnas.0914274108

He, K., Lu, H., Zheng, H., Yang, Q., Sun, G., Zheng, Y., et al. (2020). Role of dynamic environmental change in sustaining the protracted process of rice domestication in the lower Yangtze River. Quat. Sci. Rev. 242, 106456. doi:10. 1016/j.quascirev.2020.106456

He, K., and Lv, H. (2017). "The origin of marine culture: the temperature increase during the early Holocene in the Lower Yangtze River Region and rice human bones in the LYRR and drew several inferences on human subsistence strategies. The most striking finding is that humans hardly consumed marine resources even though they faced the coastline directly. Instead, they subsisted mainly on terrestrial and/or freshwater (wetland) resources and less on rice production. The specific subsistence strategies, long-term insistence, and adaptations to the unstable environment and frequent sea transgression make it possible for humans in the prehistoric period to meet the demands of settlement expansion and population increase. The uniqueness of human subsistence strategies in the LYRR expands our understanding of the means of increasing human population and social complexity.

\section{DATA AVAILABILITY STATEMENT}

The original contributions presented in the study are included in the article/Supplementary Material, further inquiries can be directed to the corresponding author.

\section{AUTHOR CONTRIBUTIONS}

The author confirms being the sole contributor of this work and has approved it for publication.

\section{FUNDING}

This paper is financially supported by National Nature Science Foundation of China (41773008) and the Project of Exploration of Chinese Civilization (2020YFC1521606). Many Thanks to Bing Yi from Department of Archaeology and Anthropology, University of Chinese Academy of Sciences for the help with producing Figure 1.

utilization and human activities on the basis of the rise of sea level," in The collection of abstracts for No. 10 symposium of palynology branch of Chinese (Chifeng: Palaeontology Society).

He, K. Y., Lu, H. Y., Li, Y. N., Ding, F. Y., Zhang, J., and Wang, C. (2020). Cultural response to Middle Holocene sea-level fluctuations in eastern China: a multiproxy approach. Boreas 49 (1), 71-88. doi:10.1111/bor.12421

Hu, Y., Li, F., Wang, C., and Richards, M. P. (2010). Stable isotope (C, N) analysis of human bones at Liyudun site, Zhanjiang, Guangdong: preliminary exploration of human lifestyles during the Neolithic in South China. Acta Anthropologia Sinica 29 (3), 264-269. (in Chinese).

$\mathrm{Hu}, \mathrm{Y} .(2018)$. Thirty-four years of stable isotopic analyses of ancient skeletons in China: an overview, progress and prospects. Archaeometry 60 (1), 144-156. doi:10.1111/arcm.12367

Hu, Y., Wang, G., Cui, Y., Dong, Y., Guan, L., and Wang, C. (2007). Paleodietary study on humans at the Sanxincun site, jintan, jiangsu. Chin. Sci. Bull. 52 (1), 85-88. doi:10.1007/s11434-007-0085-4 (in Chinese).

Kusaka, S., Hyodo, F., Yumoto, T., and Nakatsukasa, M. (2010). Carbon and nitrogen stable isotope analysis on the diet of Jomon populations from two coastal regions of Japan. J. Archaeological Sci. 37 (8), 1968-1977. doi:10.1016/j. jas.2010.03.002

Lambeck, K., Rouby, H., Purcell, A., Sun, Y., and Sambridge, M. (2014). sea level and global ice volumes from the last glacial Maximum to the Holocene. Proc. Natl. Acad. Sci. USA 111 (43), 15296-15303. doi:10. 1073/pnas.1411762111 
Lewis, J. P., Ryves, D. B., Rasmussen, P., Olsen, J., van der Sluis, L. G., Reimer, P. J., et al. (2020). Marine resource abundance drove pre-agricultural population increase in Stone Age Scandinavia. Nat. Commun. 11 (1), 2006-2010. doi:10. 1038/s41467-020-15621-1

Ling, G., Ma, C., Yang, Q., Hu, Z., Zheng, H., Liu, B., et al. (2021). Landscape evolution in the Liangzhu area since the early Holocene: a comprehensive sedimentological approach. Palaeogeogr. Palaeoclimatol. Palaeoecol. 562, 110141. doi:10.1016/j.palaeo.2020.110141

Liu, J., Milliman, J., Gao, S., and Cheng, P. (2004). Holocene development of the Yellow River's subaqueous delta, north Yellow sea. Mar. Geology. 209, 45-67. doi:10.1016/j.margeo.2004.06.009

Liu, R., Pollard, M., Schulting, R., Rawson, J., and Liu, C. (2021). Synthesis of stable isotopic data for human bone collagen: a study of the broad dietary patterns across ancient China. The Holocene, doi:10.1177/0959683620941168

Liu, Y., Deng, L., He, J., Jiang, R., Fan, D., Jiang, X., et al. (2020). Early to middle Holocene rice cultivation in response to coastal environmental transitions along the South Hangzhou Bay of eastern China. Palaeogeogr. Palaeoclimatol. Palaeoecol. 555, 109872. doi:10.1016/j.palaeo.2020.109872

Lv, H. (2017). New methods and advances on the study of the origin and evolution of Chinese prehistoric agriculture. Scientia Sinica Terrae 47 (2), 181-199. (in Chinese).

Ma, T., Rolett, B. V., Zheng, Z., and Zong, Y. (2020). Holocene coastal evolution preceded the expansion of paddy field rice farming. Proc. Natl. Acad. Sci. USA 117 (39), 24138-24143. doi:10.1073/pnas.1919217117

Minagawa, M., Matsui, A., Nakamura, S., and Sun, G. (2011). "Carbon and nitrogen stable isotope analysis of human and animal remains from Tianluoshan site: to understand food resource management of Hemudu culture,". Integrated Studies on the Natural Remains from Tianluoshan in Center for the study of Chinese archaeology, peking university and zhejiang province institute of archaeology and cultural heritage (Beijing: Cultural Relics Press), 262-269. (in Chinese).

Montgomery, J., Beaumont, J., Jay, M., Keefe, K., Gledhill, A. R., Cook, G. T., et al. (2013). Strategic and sporadic marine consumption at the onset of the Neolithic: increasing temporal resolution in the isotope evidence. Antiquity 87 (338), 1060-1072. doi:10.1017/s0003598x00049863

Ouyang, X., Hao, X., Zheng, L., Zhuo, B., and Liu, Y. (2019). Early to mid-Holocene vegetation history, regional climate variability and human activity of the Ningshao Coastal Plain, eastern China: new evidence from pollen, freshwater algae and dinoflagellate cysts. Quat. Int. 528, 88-99. doi:10.1016/ j.quaint.2019.05.027

Pan, H. (2020). Vegetation changes and human activities during the Neolithic period in the Kuahuqiao area of Zhejiang: comparison of pollen records between natural cores and archaeological profiles. Master thesis. Hefei: University of Science and Technology of China.

Pan, Y., and Yuan, J. (2018). Subsistence in the lower Yangtze River region from the neolithic to pre-qin period (part one). Relics in South 4, 111-125. (in Chinese).

Pan, Y., and Yuan, J. (2019). Subsistence in the lower Yangtze River region from the neolithic to pre-qin period (part two). Relics in South 1, 122-135. (in Chinese).

Qin, L., and Fuller, D. Q. (2019). "Why rice farmers don't sail: coastal subsistence traditions and maritime trends in early China," in Prehistoric maritime cultures and seafaring in east asia (Singapore: Springer), 159-191.

Renfrew, C., and Liu, B. (2018). The emergence of complex society in China: the case of Liangzhu. Antiquity 92 (364), 975-990. doi:10.15184/aqy.2018.60

Richards, M. P., and Hedges, R. E. M. (1999). Stable isotope evidence for similarities in the types of marine foods used by Late Mesolithic humans at sites along the Atlantic coast of Europe. J. Archaeological Sci. 26 (6), 717-722. doi:10.1006/jasc.1998.0387

Schulting, R. (2018). "Dietary shifts at the Mesolithic-Neolithic transition in Europe: an overview of the stable isotope data," in The Oxford handbook of the archaeology of diet (Oxford: Oxford University Press), 1-32.

Shoda, S., Lucquin, A., Sou, C. I., Nishida, Y., Sun, G., Kitano, H., et al. (2018). Molecular and isotopic evidence for the processing of starchy plants in Early Neolithic pottery from China. Sci. Rep. 8 (1), 17044-17049. doi:10.1038/s41598$018-35227-4$
Song, B., Li, Z., Saito, Y., Okuno, J., Li, Z., Lu, A., et al. (2013). Initiation of the Changjiang (Yangtze) delta and its response to the mid-Holocene sea level change. Palaeogeogr. Palaeoclimatol. Palaeoecol. 388, 81-97. doi:10.1016/j. palaeo.2013.07.026

Suzuki, Y., Chikaraishi, Y., Ogawa, N. O., Ohkouchi, N., and Korenaga, T. (2008). Geographical origin of polished rice based on multiple element and stable isotope analyses. Food Chem. 109 (2), 470-475. doi:10.1016/j.foodchem.2007. 12.063

Tang, L., Lv, Y., Nian, X., Lei, S., and Wang, Z. (2019). Middle Holocene seawater intrusion and human rapid response in the Yaojiang-Ningbocoastal plain, China. Quat. Sci. 39 (5), 1116-1132. (in Chinese).

Wang, S., Ge, J., Kilbourne, K. H., and Wang, Z. (2020). Numerical simulation of mid-Holocene tidal regime and storm-tide inundation in the south Yangtze coastal plain, East China. Mar. Geology. 423, 106134. doi:10.1016/j.margeo. 2020.106134

Wang, Z., Saito, Y., Zhan, Q., Nian, X., Pan, D., Wang, L., et al. (2018). Threedimensional evolution of the Yangtze River mouth, China during the Holocene: impacts of sea level, climate and human activity. Earth-Science Rev. 185, 938-955. doi:10.1016/j.earscirev.2018.08.012

Xiong, H., Zong, Y., Li, T., Long, T., Huang, G., and Fu, S. (2020). Coastal GIA processes revealed by the early to middle Holocene sea-level history of east China. Quat. Sci. Rev. 233, 106249. doi:10.1016/j.quascirev.2020.106249

Yan, D., Wünnemann, B., Gao, S., and Zhang, Y. (2020). Early Holocene tidal flat evolution in a western embayment of East China Sea, in response to sea level rise episodes. Quat. Sci. Rev. 250, 106642. doi:10.1016/j.quascirev.2020. 106642

Yang, H., and Xie, Z. (1984). Sea-level changes along the east coast of China over the last 20000 years. Oceanologia Limnologia Sinica 15, 1-13. (in Chinese).

Yoneda, M. (2017). Perspectives on methodology of isotope ecology: reconstruction of lives and society of early farmers in the Lower Yangtze River Region. Relics in South (3), 10-15. (in Chinese).

Yu, B. (2016). Preliminary exploration of pathways to pig domestication in China. Master's thesis. Hangzhou: Zhejiang University.

Zhang, G., Jiang, L., Hu, Y., Si, Y., Lv, P., Song, G., et al. (2015). Stable isotope (C, N) analysis of human and animal bones at the Tashan site, Zhejiang. Huaxia Archaeology (2), 138-146. (in Chinese).

Zhang, X., Wang, J., Xi, Z., and Qiu, S. (2003). Dietary research on ancient humans. Archaeology 2, 62-75. (in Chinese).

Zhang, Y., van Geel, B., Gosling, W. D., Sun, G., Qin, L., and Wu, X. (2020). Typha as a wetland food resource: evidence from the Tianluoshan site, Lower Yangtze Region, China. Veget Hist. Archaeobot. 29 (1), 51-60. doi:10.1007/s00334-01900735-4

Zhao, X., Tang, L., Shen, C., and Wang, S. (1994). Holocene climate change and sea level change in Qingfeng section, Jianhu, Jiangsu. Acta Oceanologia Sinica 16, 78-88. (in Chinese).

Zheng, H., Zhou, Y., Yang, Q., Hu, Z., Ling, G., Zhang, J., et al. (2018). Spatial and temporal distribution of Neolithic sites in coastal China: sea level changes, geomorphic evolution and human adaption. Sci. China Earth Sci. 61 (2), 123-133. doi:10.1007/s11430-017-9121-y

Zhu, S., Li, F., Chen, X., Fu, X., and Hu, Y. (2020). First direct evidence on human subsistence strategy and health during the middle Neolithic (9000-7000 BP) in southern China. Mancester: Antiquty. In press https://doi.org/10.15184/aqy.2020.214

Conflict of Interest: The author declares that the research was conducted in the absence of any commercial or financial relationships that could be construed as a potential conflict of interest.

Copyright $\odot 2021 \mathrm{Hu}$. This is an open-access article distributed under the terms of the Creative Commons Attribution License (CC BY). The use, distribution or reproduction in other forums is permitted, provided the original author(s) and the copyright owner(s) are credited and that the original publication in this journal is cited, in accordance with accepted academic practice. No use, distribution or reproduction is permitted which does not comply with these terms. 